\title{
Litíase biliar em paciente masculino de 6 anos: relato de caso
}

Biliary lithiasis in a six-year-old male patient: case report

Enfermedad de cálculos biliares en un paciente masculino de 6 años: reporte de caso

$$
\text { Amanda Oliva SPAZIANI }{ }^{1}
$$

Laura dos Reis CHALUB ${ }^{1}$

Cinthia ABÍLIO ${ }^{1}$

João Vitor Soares VICENTINI ${ }^{2}$

Cleidjane Furtado REZENDE ${ }^{3}$

Clerson Rodrigues MANAIA ${ }^{3}$

André Fraga RUEDA ${ }^{3}$

Leonardo FAIDIGA ${ }^{3}$

Luiz Gustavo Madi ANTONIO 4

${ }^{1}$ Graduação em Medicina, Curso de Medicina da Universidade Brasil, 15600-000 Fernandópolis - SP, Brasil ${ }^{2}$ Residente de cirurgia geral. Irmandade Santa Casa de Misericórdia de São Carlos (ISCMSC) - São Carlos, SP - Brasil ${ }^{3}$ Médico. Cirurgião geral pelo Hospital Ensino Santa Casa de Misericórdia - Fernandópolis, SP - Brasil ${ }^{4}$ Docente do Curso de Medicina da Universidade Brasil, 15600-000 Fernandópolis - SP, Brasil

Coordenador da Comissão de Residência Médica e Supervisor do Programa de Residência Médica em Cirurgia Geral na Universidade Brasil e Hospital Santa Casa de Misericórdia - Fernandópolis, SP - Brasil

\section{Resumo}

Os cálculos vesiculares, ou litíase, correspondem a depósitos de líquidos digestivos desidratados que se formam na vesícula biliar. A doença calculosa da vesícula biliar tem uma prevalência que varia de acordo com as populações estudadas. Considerando a importância do tema, esse estudo visa relatar um caso de litíase biliar em paciente do sexo masculino, seis anos, recebido em unidade de emergência com febre e dor em hipocôndrio direito e evolução para colecistectomia e herniorrafia umbilical, sete meses após, de forma eletiva. A litíase biliar é uma patologia rara em idade pediátrica, frequentemente está presente no contexto de malformações da árvore biliar ou hemólise crônica.

Descritores: Litíase; Doenças dos Ductos Biliares; Colelitíase.

\section{Abstract}

Vesicular calculi, or lithiasis, correspond to dehydrated digestive fluid deposits that form in the gallbladder. Calculi gallbladder disease has a prevalence that varies according to the population studied. Considering the importance of the topic, this study aims to report a case of biliary lithiasis in a six-year-old male patient, who was admitted to an emergency unit with fever and pain in right hypochondrium and evolution to cholecystectomy and umbilical herniorrhaphy seven months later of elective treatment. Biliary lithiasis is a rare pathology in the pediatric age, often present in the context of biliary tree malformations or chronic hemolysis.

Descriptors: Lithiasis; Bile Ducts Diseases; Cholelithiasis

\section{Resumen}

Los cálculos vesiculares, o litiasis, corresponden a depósitos de líquidos digestivos deshidratados que se forman en la vesícula biliar. La enfermedad de la vesícula biliar por cálculos tiene una prevalencia que varía según las poblaciones estudiadas. Considerando la importancia del tema, este estudio tiene como objetivo reportar un caso de litiasis biliar en un paciente masculino de seis años, ingresado en una unidad de urgencias con fiebre y dolor en el hipocondrio derecho y progresando a colecistectomía y herniorrafia umbilical, siete meses después. electivo. La litiasis biliar es una entidad poco frecuente en la edad pediátrica, que a menudo se presenta en el contexto de malformaciones de la vía biliar o hemólisis crónica.

Descriptores: Litiasis; Enfermedades de los Conductos Biliares; Colelitiasis.

INTRODUÇÃO

Os cálculos vesiculares, ou litíase, correspondem a depósitos de líquidos digestivos desidratados que se formam na vesícula biliar. É possível classificar as patologias vesiculares ou colecistopatias em benignas ou malignas, sendo as benignas classificadas em litiásicas e alitiásicas. A colecistopatia litiásica denota cálculo na vesícula. Toda a presença de cálculo na vesícula deve ser avaliada para determinação da necessidade de cirurgia ou não. A obstrução do ducto biliar por um cálculo ou coledocolitíase, em $90 \%$ dos casos, leva à inflamação aguda da vesícula, também chamada de colecistite. Surge uma cólica que logo se transforma em uma dor intensa no quadrante superior direito do abdômen, náuseas, vômitos e, eventualmente, febre, no entanto, a dor dura mais tempo. A maioria das doenças litiásicas das vias biliares requer algum tipo de procedimento cirúrgico para seu tratamento, que pode ser feito utilizando-se de duas técnicas: via laparoscópica ou aberta, sendo a via laparoscópica a mais utilizada ${ }^{1-3}$.

A doença calculosa da vesícula biliar tem uma prevalência que varia de acordo com as populações estudadas. Estudos realizados por necropsias em adultos revelaram cálculos em 12\% dos homens e $24 \%$ das mulheres. No Reino Unido, estima-se que são realizadas mais de 50.000 colecistectomias por ano e nos Estados Unidos $700.000^{4}$. Já no Brasil, no período de janeiro a novembro de 2018 foram realizadas 119.813 colecistectomias 5 .

Os fatores de risco para desenvolver cálculos biliares incluem: mulheres multíparas, com mais de 40 anos, pessoas obesas, dietas restritivas, dietas ricas em gorduras e proteínas, pacientes com doenças metabólicas, intestinais ou hematológicas, fatores genéticos e idade avançada, sendo que menos de $2 \%$ das colelitíases ocorrem em pacientes pediátricos e geralmente estão associados a doenças hemolíticas. Fatores genéticos são considerados influenciadores na formação de cálculos biliares, inclusive em inúmeros trabalhos foram identificados os genes envolvidos no processo de formação dos mesmos ${ }^{1,2,4}$.

Considerando a importância do tema, este estudo visa relatar um caso de litíase biliar em paciente pediátrico e revisar o encontrado acerca do tema na literatura. 
CASO CLÍNICO

Paciente do sexo masculino, seis anos, recebido em unidade de emergência com febre (39 graus Celsius) e dor em hipocôndrio direito. Em resposta ao exame físico, observou-se corado, hidratado, acianótico, anictérico, nutrido, eupneico e em sobrepeso (índice de massa corpórea $=27$ ). Procedeu-se com exame abdominal que apresentou hérnia umbilical irredutível, ruídos hidroaéreos normais, dor à palpação abdominal superficial e profunda em hipocôndrio direito, descompressão brusca e sinal de Murphy negativos. Já o ultrassom de abdômen total apresentou vesícula biliar sem paredes espessadas e com duas imagens hiperecogênicas, móveis, produtoras de sombra acústica posterior e diâmetro de $0,64 \mathrm{~cm}$, sugestivas de cálculos. O hemograma apresentou leucocitose com neutrofilia e linfopenia. Foi diagnosticado com litíase biliar aguda e tratado com medicamentos sintomáticos. Foi solicitado o exame eletroforese de hemoglobina que obteve resultado dentro dos padrões de normalidade (HbA1: 96,1\%; HbA2: 2,9\%; HbF: $1 \%$ ). A conduta adotada foi colecistectomia e herniorrafia umbilical, sete meses após, de forma eletiva, devido a persistência de dor em hipocôndrio direito e episódios de vômitos pós-prandiais. Evoluiu com 10 pontos do índice de Aldrete Kroulik, ruídos hidroaéreos diminuídos, som timpânico, resistente à palpação e doloroso no local da incisão no primeiro dia de pós-operatório. A incisão de Kocher e a incisão longitudinal em região umbilical permaneceram sem sinais flogísticos e o paciente evoluiu sem complicações. $\mathrm{O}$ anatomopatológico da vesícula retirada apresentou-se dentro dos padrões de normalidade.

\section{DISCUSSÃO}

A litíase biliar é uma patologia rara em idade pediátrica, possui uma incidência estimada em 0,1 $2 \%$. Frequentemente está presente no contexto de malformações da árvore biliar ou hemólise crônica, nomeadamente na esferocitose hereditária. Este último grupo representa cerca de $10-20 \%$ dos casos. A litíase biliar sintomática é ainda mais rara na criança em idade pré-escolar e a sua abordagem não está completamente estabelecida ${ }^{6}$.

Quanto à idade, estudos demonstram uma distribuição bimodal, com aumento discreto nos pacientes com idade inferior a um ano e aumento considerável na adolescência, pois é nessa fase que os cálculos de colesterol são os mais frequentes e as alterações no metabolismo do estrógeno podem resultar em litogenicidade aumentada da bile ${ }^{7}$.

Assim, adolescentes com sobrepeso apresentam o dobro de probabilidade de ter cálculos biliares, quando comparados a adolescentes com índice de massa corpórea normal. Para os obesos, esta chance cresce quatro vezes mais, e para aqueles com obesidade grave, a probabilidade de sofrer dessa condição é seis vezes maior ${ }^{7}$.

Estudos afirmam que a litíase biliar tem aumentado em crianças, seja pelo maior número de situações clínicas predisponentes, particularmente a obesidade, como pela melhora dos métodos diagnósticos. Atualmente, os fatores de risco para litíase biliar, entre as crianças assemelham-se aos dos adultos, como obesidade, uso de anticoncepcionais orais, doenças hepatobiliares, gravidez e história familiar $^{7}$.

A maioria das crianças e adolescentes apresenta sintomatologia, diferentemente dos adultos que são assintomáticos para tal patologia ${ }^{7}$. As crianças têm queixas abdominais, dor no quadrante superior direito e vômitos são observados nas crianças mais velhas, intolerância a alimentos gordurosos apenas em maiores de seis anos e os menores de cinco anos tendem a se apresentar com sintomas inespecíficos. A habilidade de localizar a dor ou de relatar os sintomas relacionados à alimentação como empachamento, náuseas e intolerância a alimentos gordurosos depende da idade. Já irritabilidade, particularmente após as refeições, pode sugerir a possibilidade de cálculos, especialmente em prematuros ou em pacientes com antecedente enterocolite necrosante ${ }^{6}$.

Segundo um estudo de coorte, realizado nos Estados Unidos, detectaram-se 766 casos de litíase biliar entre os 510.816 adolescentes e crianças que participaram do estudo, ocorreu prevalência de $0,1 \%$. Os autores observaram que o número total de casos de cálculos biliares amplia com o aumento do peso, entretanto a associação foi mais forte em meninas do que em meninos. Vários estudos têm demonstrado maior frequência de litíase biliar no sexo feminino, está associada à doença do cálculo biliar, especialmente durante os anos férteis, devido os estrogênios aumentarem a secreção de colesterol e diminuem a de sais biliares, enquanto progestagênios atuam por redução da secreção de sais biliares e do esvaziamento da vesícula, levando à estase ${ }^{7}$.

É válido citar que a doença calculosa tem seu primeiro pico de incidência no primeiro ano de vida, pois os lactentes possuem uma bile mais litogênica, devido a um maior índice de saturação do colesterol e um menor tempo de nucleação. Nessa faixa etária, não há prevalência de um sexo sobre o outro. Além disso, os lactentes possuem outros fatores de risco, como administração prolongada de nutrição parenteral, doença ileal, prematuridade, desidratação, imaturidade daglicuroniltransferase hepática ou terapia com ceftriaxona, os quais provocam um distúrbio transitório da bile que a predispõe à formação dos cálculos. Os prematuros, por sua vez, estão sujeitos fatores de risco adicionais para a colelitíase, como as múltiplas transfusões e a sepse por gram-negativo. Já o segundo pico se dá na 
adolescência, quando passa então a predominar os cálculos de colesterol, devido às alterações no metabolismo dos estrogênios característicos dessa fase. Nesta fase, já começa o predomínio do sexo feminino. Outros fatores de risco para colelítiase infantil são a trombose da veia porta, crianças submetidas à cirurgia abdominal, cirurgia cardíaca ou cardiopatas, história familiar positiva, antecedente de tratamento para câncer, jejum prolongado, infecção do trato urinário, deficiência de $\operatorname{Ig} \mathrm{A}$, transplante de medula óssea, síndrome de Down, além das doenças que resultam em disfunção intestinal, como a síndrome do intestino curto, as diarreias graves, as doenças inflamatórias intestinais, a fibrose cística e as ressecções de delgado ${ }^{8}$.

A ultrassonografia transabdominal superior é o meio de diagnóstico de eleição na litíase biliar, com uma sensibilidade e especificidade superior a $95 \%$, tem a capacidade de demonstrar o tamanho e a localização do cálculo, sendo este o meio de diagnóstico utilizado em todas as crianças ${ }^{7}$.

Em relação à atitude terapêutica, a maioria dos autores preconizam uma atitude expectante nas crianças abaixo dos dois anos e assintomáticas, devido à grande probabilidade de resolução espontânea. Na criança mais velha e sintomática a colecistectomia é o tratamento cirúrgico de eleição. A decisão entre tratamento conservador e colecistectomia depende da idade e da gravidade dos sintomas. Em geral, nos pacientes assintomáticos ou com sintomas atípicos, nos lactentes e nos pacientes com nutrição parenteral está indicado o tratamento conservador com acompanhamento clínicoultrassonográfico periódico. Já nos pacientes sintomáticos (principalmente naqueles com sintomas típicos de epigastralgia ou dor em quadrante superior direito com intolerância alimentar) e naqueles com cálculos calcificados (pela baixa probabilidade de resolução espontânea) e com cálculos não pigmentados, deve ser indicado solução cirúrgica, de preferência por via laparoscópica ${ }^{8}$. Mas segundo estudos, o tratamento para a litíase biliar é a videolaparoscopia devido apresentar o melhor acesso cirúrgico. Há menor ou mínimo sangramento, os orifícios deixam cicatrizes mínimas quando não desaparecem, obtendo-se o melhor efeito estético até agora possível. Quando se fecha o plano músculoaponeurótico no orifício, não ocorrem hérnias incisionais. As microincisões apresentam menor risco de aderências à parede, serosidade e hematomas. Utilizam-se muito menos fios de sutura, pois não há laparotomia. Pela não exposição e menor manipulação visceral quase não ocorrem íleo paralítico e distensão intestinal pós-operatória, permitindo a realimentação precoce da criança. $\mathrm{O}$ tempo necessário de internação torna-se menor, com menor risco de infecção hospitalar. A laparoscópica é segura e pode ser bastante eficaz em crianças, tem baixo risco de complicações e provavelmente reduz o tempo de internação hospitalar. Há ainda debates sobre o papel da colangiografia intraoperatória que, embora exequível, é tecnicamente difícil em crianças, requer habilidade e pode ser demorada ${ }^{6}$.

\section{CONSIDERAÇÕES FINAIS}

Desse modo, a epidemia de obesidade infantil contribui significativamente para aumentar o risco de litíase biliar em crianças e adolescentes. Os médicos pediatras e cirurgiões devem estar preparados para lidar com essa patologia na população pediátrica, devido a obesidade e suas complicações presentes nessa faixa etária. Os fatores de risco para litíase biliar na faixa etária jovem são semelhantes aos fatores de risco da população adulta: sexo feminino, obesidade, gravidez e anticoncepcionais orais, além do anteriormente conhecido, a doença hematológica.

Ressalta-se a necessidade de estudos epidemiológicos para definir a real incidência de litíase biliar na população pediátrica, principalmente nos que apresentam sobrepeso e obesidade, além de estudos para definir os reais fatores de risco para litíase biliar na faixa etária.

\section{REFERÊNCIAS}

1. Oliveira RS, Silva PD, Queiroz CAS, Terra-Júnior JA, Crema E. Prevalence of bacteriobilia in patients undergoing elective colecystectomy. Arq Bras Cir Dig. 2018;31(3):e1392.

2. Leão JD, Silva LR, Martins LR, Andréa Fernanda Lopes dos Santos. Associação entre cálculos biliares e consumo alimentar. Rev Interdiscip. 2017;10(4):31-8.

3. Oliu Lambert $\mathrm{H}$, de la Cruz Castillo NA, Piña Prieto LR, Domínguez González EJ, Romero García LI. Caracterización de pacientes con litiasis vesicular operados por mínimo acceso. Medisan. 2016;20(9):69-76.

4. Teive MB, Cantarelli MP, Mendes AC, Dametto G, Matiollo C. A composição química dos cálculos da vesícula biliar - um estudo em pacientes de Santa Catarina. ACM Arq Catarin Med. 2018;47(1):133-40.

5. TabNet: procedimentos hospitalares do SUS colecistectomia. Brasília, DF: DATASUS; 2018.

6. Leite S, Silva HM, Guerra IC, Flores H, Carvalho F, Silva ES et al. Litíase biliar em idade pediátrica: que abordagem?. Nascer e Crescer. 2015;24(Suppl 2):S14.

7. Nunes MMA, Medeiros CCM, Silva LR. Litíase biliar em adolescentes obesos atendidos em ambulatório. J Pediatr (Rio J.). 2014;90(2):203-8.

8. Suavinha, FF, Faria ÉF, Costa Neto DB, Coelho FJT. Síndrome colestática na infância: relato de caso. Rev Pato Tocantins. 2016;3(2):11-20. 


\section{CONFLITO DE INTERESSES}

Os autores declaram não haver conflitos de interesse.

\section{AUTOR PARA CORRESPONDÊNCIA}

\section{Amanda Oliva Spaziani}

Faculdade de Medicina, Campus Fernandópolis

Universidade Brasil

e-mail: spazianimedicina@gmail.com

Submetido em 16/07/2020

Aceito em 20/04/2020 